\title{
GRAPH THEORETICAL MODELING AND ANALYSIS OF INFORMATION SYSTEM IN SUPPLY CHAIN.
}

\author{
SABAREESAAN.K.J', AGRAWAL.V.P.', JAYA.J. ${ }^{3}$ \\ ${ }^{1,2}$ Mechanical Engineering Group, Birla Institute of Technology and Science-Pilani \\ Goa Campus, Zuari Nagar, Goa 403 726, India \\ ${ }^{3}$ Anna University, Chennai, India \\ Email: 1k_j_sabareesaan@yahoo.co.in
}

\begin{abstract}
Companies are attempting to find ways to improve their flexibility and responsiveness and in turn Competitiveness by changing their operations strategy, methods and technologies that include the implementation of supply chain management (SCM) paradigm and information technology (IT). IT has a tremendous influence on achieving an effective SCM. This study derives a new mathematical model aimed to consider virtual design of information system for effective supply chain management. An attempt is made in this article to identify different subsystems and other constituents of five main subsystems - Strategic Planning of IT, Virtual Enterprise, E-Commerce, IT Infrastructure and Knowledge and IT Management system of total information system in SCM.Graph theoretical models, variable permanent adjacency matrix models, and permanent functions of these systems based on graph theory-matrix algebra-permanent function methodology are developed .Analytical tests for structural analysis of information system are derived to select optimum constituents in each of these five systems of information system in SCM.Coefficient of similarity and dissimilarity are useful aid to take right decisions between alternative solutions. Permanent function is a unique representation and to be used by SCM solution providers for coding, evaluation, comparison, ranking, and optimum selection. Structural models are useful for basic understanding of complete information system, leading to right decisions for business strategies. Step by step procedure is developed to assist SCM solution providers to implement the proposed method in a right way. Usefulness of the present methodology is also illustrated.
\end{abstract}

Key words: Information System (IS) in SCM, Structural modeling, Digraph Approach, Permanent function.

\section{INTRODUCTION AND LITERATURE SURVEY}

In Recent days the business environment is rapidly changing because of globalization, tough competition, highly demanding knowledgeable customers, and information and communication technologies. According to Simchi-Levi et al. (24), SCM is a set of approaches utilized to effectively integrate suppliers, manufacturers, warehouses, and stores, so that merchandise is produced and distributed at the right quantities, to the right locations, and at the right time, in order to minimize system wide cost while satisfying service level requirements. SCM is based on the integration of all activities that add value to customers starting from product design to delivery. Supply chains are often complex systems of interdependent activities and processes associated with the flow of products, services and information from the original supplier of raw materials through to the final consumer (Handfield and Nichols, 1999), managing them is often facilitated by IT (e.g. Manrodt and Davis 1993). ccording to Christopher, the use of information technology to share data between buyers and suppliers is, in effect, creating a virtual supply chain. Virtual supply chains are informationbased rather than inventory-based (6). To achieve agility in supply chain, information systems are recognized as being a critical factor in a similar way to the contribution flexible manufacturing systems made in the past to agile manufacturing. The rapid development of information technology and the internet, together with the emerging trend towards global logistics systems has prompted an increasing emphasis to be placed on the circulation function of the supply chain $(23,20)$. Graham and Hardaker highlight the role of the Internet in building commercially viable supply chains in order to meet the challenges of virtual enterprises. Helbig, advocates that IT supports the reorganization of communication and coordination processes by enhancing information distribution, availability, presentation, and processing. Many studies indicate that for a business to ensure its success, the organization must actively strive to develop enhanced supplier participation, integrated relationships with its suppliers, and a strategic plan for information technology integration. The alignment between manufacturing and business strategies the main implication is that the production/manufacturing function should be involved in strategic decision-making $(11,12,19)$. Chen et al. applied a structural equation model approach to examine the links among strategic purchasing, supply management, and firm performance.Rosenzweig et al. highlighted the mediating role of manufacturing-based competitive capabilities in supply chain management. Kannan and Tan developed correlation analysis approach to examine that linkages and impact of JIT, TQM, and SCM on business performance. Droge et al. studied the effects of integration practices reaching across firm boundaries to involve suppliers and customers on time-based performance and on overall firm performance.Kuei et al. 
(2001) presented an empirical study of the relationship between supply chain management and organizational performance (OP), and some papers have explored the relationship between information systems and supply management performance (Narasimhan and Kim, 2001; Lin et al., 2003; Coronado, 2003;Gunasekaran and Ngai, 2004; Helo and Szekely, 2005).In SCM, IT can support and improve the coordination of activities and communication within a company and across supply chain members to raise efficiency and reduce costs. One of the major ITenabled potentials for improvement of SCM are e marketplaces or trade platforms on the internet (Hausen, 2006), which especially support the cross functional and cross enterprise aspect with the vision of supply chains going beyond procurement, production and distribution activities of a single company. The improvement of supply chain processes across companies requires not only the availability of appropriate information infrastructures for realtime information, but also close collaboration between companies for information sharing as well as the integration of all participating companies. SCM across companies is supported by information and communication technologies (ICT) that include electronic data interchange (EDI), the Internet and World Wide Web (WWW) Gunasekaran (2004), IT-based tools such as advanced planning and scheduling (APS) systems, or concepts such as collaborative planning, forecasting, and replenishment, efficient consumer response (ECR) or vendor-managed inventories (VMI) and improvements in mathematical optimization of supply chains (Disney etal., 2004).

Many studies have stressed the partial relationships among information technology application with supply chain performance (Narasimhan and Kim, 2001; Kuei et al., 2001; Lin et al., 2003; Choy et al., 2003; Soliman and Youssef, 2003; Droge et al., 2004; Gunasekaran and Ngai, 2004; Chen et al., 2004; Kannan and Tan, 2005). However, a structural framework for these constructs is seldom found.Chinho el al (2006) proposed a conceptual structural equation model to demonstrate the direct and indirect impact of supply chain participation strategy (SCPS), information technology application (ITA),manufacturing participation strategy (MPS) on customer satisfaction (CS) and organizational performance (OP) from a strategic perspective and he found that this model is a very useful source of information and a notice for managers to achieve greater success in implementing the supply chain systems.

In the logistics/supply chain context, Bowersox and Daugherty (1995) outlined that IT is key in supporting companies creating strategic advantage by enabling centralized strategic planning with dayto- day centralized operations. It is therefore not surprising that many firms have begun to develop strategies focusing on using information technology as a resource to facilitate the effective collection and utilization of information (Bharadwaj, 2000).SCM is inherently information intensive. A successful SCM approach necessitates two important technological requirements for sharing information: (1) Stable and secure electronic linkages between companies; and (2) an integrated, High-bandwidth environment to provide a host of SCM support services.

The rapid development of information technology and the internet, together with the emerging trend towards global logistics systems has prompted an increasing emphasis to be placed on the circulation function of the supply chain (Sanders and Premus, 2002; Trappey et al., 2004; Rahman, 2004).Narasimhan and Kim (2001) proposed that Earl's classification not only was applicable to the internal value chain of a firm, but could also be extended to the company's supply chain, linking suppliers, and customers. Several studies have examined the impact of information technology on the supply chain (Byrd and Davidson, 2003;Kearns and Lederer, 2004). Liao et al. (2004) indicated that the effect of implementation of IT functions on a business becomes a critical issue not only theoretically but also is practice.

Electronic Commerce (E-commerce) technologies are well suited to cater to demands and as such, they have an integral part to play in creating and facilitating new forms of SCM (Nambisan, 2000). Nothing appears to have had the same effect on SCM as E-commerce, which resulted in changing the focus of SCM from engineering efficient manufacturing processes to the coordination of activities in the supply chain network through knowledge management (Tan, Shaw \& Fulkerson, 2000). In other words, Ecommerce technically made the SCM viable and facilitated SCM use in different industries. Ecommerce can take a variety of forms such as EDI, direct link-ups with suppliers, Internet, Intranet, Extranet, electronic catalog ordering, and e-mail. The benefits offered by EDI pale in comparison with those available via E-commerce-based technologies (Cross, 2000). Some may even view the Internet's impact on SCM as rivaling that of the interstate highway system on the transportation industry (Carter el al., 2000). E-commerce-based technologies are capable of delivering a holistic system that incorporates what EDI is already capable of accomplishing-combining it with broadbased access and cost effective, real-time document transmission and distribution (e.g., Larson and Kulchitsky, 2000).

For many decades, intermediaries within a supply chain have used electronic data interchange (EDI). EDI allows for data to be electronically sent between different firms and different applications. The traditional architecture of EDI most typically required using a value- 
added network (VAN). The VAN provided the network and translation services necessary to EDI, converting the data from one system to another. This service was costly, and traditional EDI was cost-prohibitive for small and medium sized firms. Today, however, the public internet is replacing the costly VAN providers. Two technologies are driving this change: extensible markup language (XML) and virtual private networks (VPN) (Wang and Zhang, 2005).XML is a markup language used to design web pages. Unlike hypertext markup language, XML is able to use tags that communicate specific meaning. This feature allows for data to be displayed in a variety of formats as well as being sent in real-time across the internet. Much like the VAN translation service in the past, XML allows for intermediaries to send data to and from different applications. Perhaps the largest question of using the public internet to communicate confidential data is that of security. Traditionally, using a VAN meant leasing a secure, point-to-point network. The tradeoff, as mentioned above, was cost. VPNs use the public internet to send data, but create a secure connection using authentication methods in combination with encryption. When used in conjunction with XML, VPNs allow for data to be securely sent between different applications.

From the above literature, no body considered integration of all sub systems and the same time no mathematical model is proposed for the application of IT to achieve an effective SCM. In the proposed framework of IS-SCM, care has been taken to make use of the opportunities that were identified from the other frameworks. An attempt has also been made to reduce the shortcomings of the Information system (IS) in supply chain frameworks.

The graph theoretic systems approach is extensively applied in various disciplines of science and technology. Ambekar and grawal (2003) applied the graph theoretic methodology to the structural similarity, classification, isomorphism of kinematic chains, and mechanisms. Gandhi and Agrawal (1996) successfully applied the graph theory to failure cause analysis, reliability, and wear analysis.

The present paper introduces the graph theoretic approach to the Information systems in Supply chain management (IS-SCM). With the help of the graph theory, the structure graph is proposed by considering the interdependence between the various aspects of organization. The design graph is the first mathematical model to consider all the structure aspects in an integrated and concurrent way in the proposed methodology. To extend the model, a structure matrix is proposed for easy storage and retrieval in the computer database. Finally, using permanents, a multinomial is proposed, which is unique in representation of the structure system. A structure index is also derived, which is more useful for deciding the overall structure acceptability according to the Information System requirements at the conceptual stage itself. Structural modeling and analysis of information system is the first step towards achieving supply chain systems in this highly competitive business environment. Since it has comprehensive correlation of performance measures with structure, the performance modeling will be reported in future publications.

Begin your paper here. This paragraph represents the standard font and layout for individual paragraphs. All references within the text should be numbered consecutively with the numbers in parentheses as shown at the end of this sentence (3). To use this template, replace the text in this template with your text.

\section{IDENTIFICATION OF SUBSYSTEMS OF INFORMATION SYSTEM (IS) IN SCM AND ITS BLOCK DIAGRAM SHOWING INTERACTION BETWEEN SUBSYSTEMS}

It is clear from the detailed literature review that information system in SCM must consider Strategic Planning of IT, Virtual Enterprise E-Commerce and from the point of view of Infrastructure with the integration of Knowledge and IT Management system (Gunasekaran et al.2004).To address all the issues of supply chain in an integrated and concurrent engineering way, different systems of Information System are classified in five groups as

S1 = Strategic Planning of IT sub system [SPSS]

S2 $=$ Virtual Enterprise subsystem [VESS]

S3 $=$ E-Commerce subsystem [ECSS]

S4 = Infrastructure subsystem [INSS]

S5 = Knowledge and IT Management subsystem [KITMSS]

Each of these five subsystems $\mathrm{Si}, \mathrm{i}=1, \ldots, 5$ is identified by a hierarchical tree to indicate its contribution and scope through its sub-sub systems in total Information System (IS) in SCM. Each of these hierarchical trees need to be replaced by corresponding block diagram showing interaction between its systems, as each subsystem is a system in itself. These five subsystems are also integrated through their interactions between them in the form of a block diagram as shown in Figure 1. Each of these subsystems are further subdivided into sub system as shown in Table 1. 


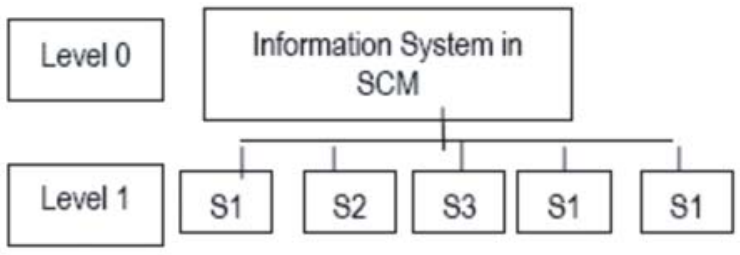

Fig. 1. Structural Constituents of Information System in SCM

\begin{tabular}{|c|c|}
\hline \multirow{12}{*}{$\begin{array}{c}\text { Strategic } \\
\text { Planning of IT } \\
\text { sub Systems } \\
\text { (S1) }\end{array}$} & Top management participation \\
\hline & Long term business plan \\
\hline & $\begin{array}{l}\text { Global market and } \\
\text { competitiveness }\end{array}$ \\
\hline & Virtual Enterprise \\
\hline & Agility and cost \\
\hline & Global outsourcing \\
\hline & E-business \\
\hline & Strategic partnerships \\
\hline & Mergers and Acquisitions \\
\hline & New products/services \\
\hline & New market creation Reputation \\
\hline & Integrated systems \\
\hline \multirow{8}{*}{$\begin{array}{c}\text { Virtual } \\
\text { Enterprise } \\
\text { subsystems } \\
\text { (S2) }\end{array}$} & Competencies \\
\hline & Collaborative network of firms \\
\hline & Virtual teaming \\
\hline & Virtual manufacturing, \\
\hline & Virtual logistics \\
\hline & $\begin{array}{l}\text { Enterprise resource planning } \\
\text { systems }\end{array}$ \\
\hline & $\begin{array}{l}\text { E-Commerce including B2B, } \\
\text { B2C and B2A }\end{array}$ \\
\hline & Training and Education in IT \\
\hline \multirow{8}{*}{$\begin{array}{c}\text { E-Commerce } \\
\text { subsystem } \\
\text { (S3) }\end{array}$} & Global market and competition \\
\hline & Digital firms \\
\hline & Access to alternative markets \\
\hline & Opportunities for Networking \\
\hline & Technological advances \\
\hline & $\begin{array}{l}\text { Enhanced strategic alliances } \\
\text { with partners }\end{array}$ \\
\hline & $\begin{array}{l}\text { Reduction in cost and increase } \\
\text { in agility }\end{array}$ \\
\hline & Open communication \\
\hline
\end{tabular}

\begin{tabular}{|c|c|}
\hline & Enhanced teamwork \\
\hline & Customer relationship management \\
\hline & E-work \\
\hline \multirow{14}{*}{$\begin{array}{l}\text { Infrastructure } \\
\text { subsystems } \\
\text { (S4) }\end{array}$} & Fitness for the Business process \\
\hline & Internet connectivity \\
\hline & IT investment \\
\hline & Enterprise resource planning \\
\hline & Software and hardware availability \\
\hline & Autonomous agents \\
\hline & EDI \\
\hline & E-commerce platform \\
\hline & XML, LAN, MAN, WAN \\
\hline & Intranet \\
\hline & Extranet \\
\hline & IT skills \\
\hline & Training and Education in IT \\
\hline & IT evaluation \\
\hline \multirow{13}{*}{$\begin{array}{l}\text { Knowledge and } \\
\text { IT Management } \\
\text { subsystem } \\
\text { (S5) }\end{array}$} & IT training and education \\
\hline & Core competency training \\
\hline & Investment in knowledge capital \\
\hline & E-learning \\
\hline & E training \\
\hline & Groupware \\
\hline & Multimedia \\
\hline & Workflow technologies \\
\hline & Cross functional training, \\
\hline & Job rotation \\
\hline & Reward and incentive schemes \\
\hline & Empowerment and team work \\
\hline & Contribution to knowledge capital \\
\hline
\end{tabular}

Table 1. Information System with subsystem and sub subsystems

\section{BLOCK DIAGRAM REPRESENTATION}

The Information System is considered to be a collection of a number of basic structural constituents, $\mathrm{Si}$, i $=1,2,3,4,5$. These constituents are connected with each other through different forms of bonding and interactions. The constituents and interactions forming a Information System (IS) in SCM are shown in Figure 2 with the help of a schematic diagram. Blocks show constituents, lines show connectivity/interaction, and arrows show directional 
bonding/interaction. However, schematic diagram is a good representation of Information System for a better understanding of its structure but it is not a mathematical entity.

Hence, it is not possible to derive different results as no mathematical operation can be carried out. It is proposed to introduce a mathematical representation of Information System in an attempt to develop a systems model for analysis and synthesis of the Information System, which will be useful to carry out analysis of an existing organization for improvement and cost reduction apart from other benefits in the competitive world (Deo, 2000; Robinsion and Fould, 1980),

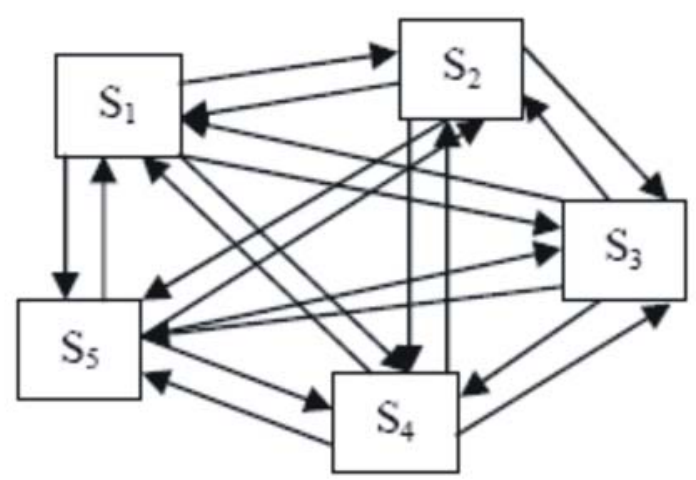

Fig. 2. Block diagram of Information System showing interactions

\section{GRAPH THEORETIC REPRESENTATION}

Information System (IS) in SCM is considered to be a collection of a number of basic structural constituents/subsystems, e.g., Strategic Planning of IT, Virtual Enterprise E-Commerce etc. as shown in Figure 1. These constituents are connected with each other through different forms of bonding and interactions. The constituents and interactions forming a Information System are shown in Figure 2 with the help of a schematic diagram. Blocks show matrix is square and symmetric. The IS-SCM connectivity matrix (COIS- SCM) representing the undirected graph shown in Figure 4. is written as:

$$
A=\left[\begin{array}{lllll}
0 & 1 & 1 & 1 & 1 \\
1 & 0 & 1 & 1 & 1 \\
1 & 1 & 0 & 1 & 1 \\
1 & 1 & 1 & 0 & 1 \\
1 & 1 & 1 & 1 & 0
\end{array}\right]
$$

In the above matrix A, the value of Sii, is zero. An offdiagonal system with value 0 or 1 represents the interdependency or connectivity between subsystems. The matrix does not contain full information about subsystems and interaction. The diagonal systems are 0 because there is no interdependency/connectivity of any subsystem with itself. Equation (1) stores connectivity information of the system only. To characterize the IS$\mathrm{SCM}$, a characteristic matrix is defined.

\section{IS-SCM CHARACTERISTIC MATRIX (CM- IS-SCM)}

Let us consider an identity matrix $\mathrm{I}$, and $\mathrm{S}$ as the variable representing subsystems of the Information System. The characteristic matrix defined used in mathematics (Eckstein and Rohleder, 1998) is used to characterize the Information System. The Information System characteristic matrix, $B$, for the undirected graph shown in Figure 4 expressed as [SI-A], where A is the adjacency matrix represented in Equation (1) as.

$$
B=\left[\begin{array}{cccccc}
1 & 2 & 3 & 4 & 5 & \text { Vertex } \\
S & -1 & -1 & -1 & -1 \\
-1 & S & -1 & -1 & -1 \\
-1 & -1 & S & -1 & -1 \\
-1 & -1 & -1 & S & -1 \\
-1 & -1 & -1 & -1 & S
\end{array}\right] \begin{gathered}
2 \\
3 \\
5
\end{gathered}
$$

Determinant of matrix $B$ gives

Det $(B)=$ S5-10xS3-20xS2-15xS-4 [2a]

Determinant of characteristic matrix $B$ equation e.g. (2a) is called characteristic polynomial and characteristic of the Information System. It is powerful characterizing invariant of the system. At this stage the problem is now considered from combinational / discrete mathematics point of view. In the above matrix $B$, the value of all diagonal systems is the same (i.e., all information system (IS) subsystems are assumed to be identical which may or may not be true in practice, since all information system(IS) subsystems have different characteristics depending on various parameters representing them). Interdependencies between the subsystems have been assigned values of 0 and 1 depending on whether it is there or not. This does not represent varying degree of influence of one subsystem over the other subsystems and also distinct function of these five subsystems. To consider this, another matrix called the IS-SCM variable characteristic matrix is proposed. 


\section{IS-SCM Variable Characteristic Matrix (VCMIS- $\mathrm{SCM}$ )}

The Information System variable characteristic matrix takes into consideration, the effect of different information system (IS) subsystems and their varying degrees of interactions. The digraph in Figure 3 is considered for defining VCM- IS-SCM. Let Sis and Sijs represent nodes and edges, respectively, in the digraph. Consider a square matrix $\mathrm{C}$ with offdiagonal systems $\mathrm{Sij}$ representing varying interactions between the information system (IS) subsystems, i.e., instead of 1 (as in the matrix of Equation (1)). Another matrix $D$ is taken with diagonal systems $\mathrm{Si}$, i=1, 2, 3, 4, 5 where the Si represents five different subsystems as shown in graph Figure 3 . As these are distinct systems, Si will represent varying inheritance of structural attributes in these subsystems. Considering matrices $\mathrm{C}$ and $\mathrm{D}, \mathrm{VCM}$ - IS-SCM is expressed as $\mathrm{H}=[\mathrm{D}-\mathrm{C}]$

$$
H=\left[\begin{array}{ccccc}
S_{1} & -S_{12} & -S_{13} & -S_{14} & -S_{15} \\
-S_{21} & S_{2} & -S_{23} & -S_{24} & -S_{25} \\
-S_{31} & -S_{32} & S_{3} & -S_{34} & -S_{35} \\
-S_{41} & -S_{42} & -S_{43} & S_{4} & -S_{45} \\
-S_{51} & -S_{52} & -S_{53} & -S_{54} & S_{5}
\end{array}\right]
$$

The above matrix, $\mathrm{H}$, permits us to represent complete information about all the five subsystems and interactions amongst these maintenance system of any organization. This information is useful for analysis, design, and implementation of new Information System at conceptual stage or for optimization purposes. The matrix provides a powerful tool through its determinant, called the variable characteristic IS-SCM multinomial (VC- ISSCM). This is a characteristic of the system and represents the complete IS-SCM, considering the effects of information system (IS) subsystems and their interactions. Due to consideration of selective interaction present between the information system subsystems in real application of typical industry, some of the off diagonal systems in the matrix, H, i.e., in Equation (3), may be zero.

The determinant of the matrix, $\mathrm{H}$, i.e., the variable characteristic Information System multinomial, carries positive and negative signs with some of its terms. The multinomial, in the symbolic terms, contains complete information of the IS-

SCM. If we replace symbols $\mathrm{Si}$ and Sij with their numerical values, information will be lost. Hence, complete information in the Information System will not be obtained as some will be lost due to the addition and subtraction of numerical values of the terms of the multinomial systems (i.e., Sis and Sijs). Thus the multinomial of the matrix, $\mathrm{H}$ in Equation (3), does not retain complete information concerning the Information System under certain conditions but in symbolic notations this multinomial is definitely unique characteristics equation. To avoid the loss of structural information during mathematical processing, another term IS-SCM variable permanent matrix (VPM- IS-SCM) is introduced.

\section{IS-SCM VARIABLE PERMANENT MATRIX (VPM- ISSCM)}

To develop a unique and comprehensive model of information system(IS)represented by a schematic diagram (Figure 2) and a digraph (Figure 3), another entity permanent and permanent matrix, frequently used in combinatorial mathematics (Marcus, M. and Minc, H., 1965; Mohan, M., Gandhi, O.P. and Agrawal, V.P., 2003) is proposed. Let the permanent matrix of five-subsystem SCM be defined as

$H=\left[\begin{array}{ccccc}S_{1} & S_{12} & S_{13} & S_{14} & S_{15} \\ S_{21} & S_{2} & S_{23} & S_{24} & S_{25} \\ S_{31} & S_{32} & S_{3} & S_{34} & S_{35} \\ S_{41} & S_{42} & S_{43} & S_{4} & S_{45} \\ S_{51} & S_{52} & S_{53} & S_{54} & S_{5}\end{array}\right]$

This matrix $\mathrm{H}$, equation (4) is a most general matrix representation for a information system (IS) modeled as five-subsystem. The diagonal systems S1, S2, S3, S4, S5 represent the contribution of the five critical subsystems in producing a Information System and the offdiagonal systems represent interdependencies of subsystems in the matrix. This model permits the complete representation of the contribution of each subsystem and interaction quantitatively without any loss of information in both multinomial form and single numerical index form. The complete permanent function of the graph, equation (4) is written as

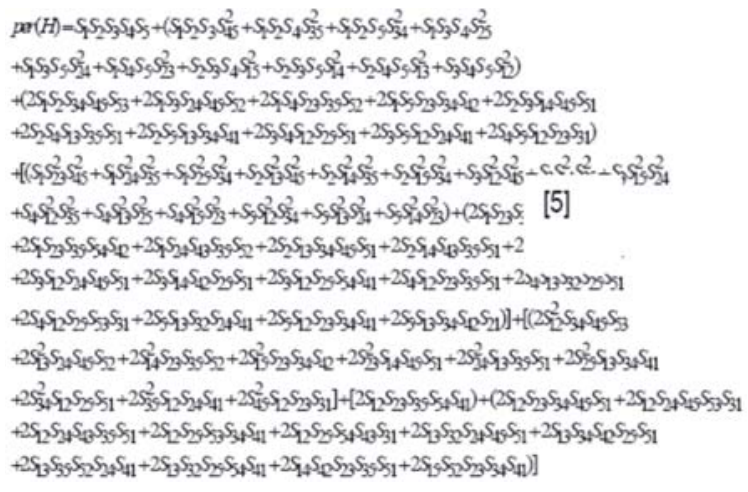




\section{Permanent Function Representation}

Both digraph and matrix representations are not unique as these models change by changing the labeling of nodes. To develop a unique representation of Information System, independent of labeling, a permanent function of the matrix VPM- IS-SCM is proposed for this purpose. Permanent is a standard matrix function and is used in combinatorial mathematics (Eckstein and Rohleder, 1998; Marcus and Minc, 1965). The permanent function is obtained from a matrix in a similar manner as its determinant. Negative sign appears in the expansion of determinant while in the permanent, i.e., the variable permanent function, only positive signs appear. These computation processes result in a multinomial (Equation (6)) whose every term has a physical significance related to the Information System. This multinomial representation includes all the information regarding various constituents as subsystems, sub subsystems, and interactions amongst them. The variable permanent function for a information system modeled as five subsystems information system is derived from matrix representation shown in Equation (4).

The permanent function representation of complete permanent matrix, equation (4) consists of $n$ ! terms. In these case it is $5 \times 5$ matrix,so it contains 5 ! Tems i.e., 120 terms. These terms are arranged in $(n+1)$ groups i.e. $(5+1)$ $=6$ groups. Different terms of permanent function consists of structural components e.g. subsystems $\mathrm{Si}$ and directed loops of two and more subsystems,

i.e. Si , Sj , (Sij Sji), (Sij Sjk ,Ski , Sik Skj Sji ), (Sij Sjk Skl Slj , Sil Slk Skj Sji) etc.

When directed graph is converted into undirected graph, Sij Sji is converted into a dyad S2ij; (Sij Sji),(Sij Sjk ,Ski , Sik Skj Sji is converted into 2 Sij Sjk, Ski and (Sij Sjk SkI Slj , Sil Slk Skj Sji) is converted into 2 Sij Sjk SkI Slj etc.

\section{IX . EVALUATION OF SI}

The diagonal systems of the matrix in Equation (4) correspond to the five subsystems that constitute a information system (IS). The values of these diagonal systems $\mathrm{S} 1, \mathrm{~S} 2, \ldots, \mathrm{S} 5$ are calculated as:

S1 = per (EP1); S2 = per (EP2); S3 = per (EP3);

S4 $=$ per (EP4); S5 = per (EP5) [6]

Where EP1, EP2, EP3, EP4, EP5, are the variable permanent matrices for five subsystems of the Information System. The procedure for calculating S1, S2, S3 . . S5 is the same as for calculating per (E) of Equation (5). For this purpose, the subsystems of Information System are considered, and the procedure given below is followed:
1. The schematics of these subsystems are drawn separately by considering their various sub subsystems.

2. Identifying the degree of interactions, interconnections, dependencies, connectivity, etc. between different subsubsytems.

Digraph representations (like Figure 3 ) of five subsystems $\mathrm{Si}(\mathrm{i},=1,2, \ldots, 5)$ are drawn first separately to obtain their matrix equations (like Equation (4)) i.e. EP is and then their permanent functions. The off-diagonal terms $\mathrm{Sij}(\mathrm{i}, \mathrm{j}=1,2, \ldots, 5)$ of matrix equation (4) gives the connections between the systems Si and Sj. Depending upon the type of structural analysis, Sij can be represented as multinomial, graph, matrix or by some analytical model. To get the exact degree of interactions, interconnections, dependencies, connectivity, etc. between subsystems or sub subsystems we may have to consider the views of technical team experts. A team of experts selected from organization to consider all the issues involved from the point of view of engineering, science, technology, and business strategy. The final decision on the values of Sis and Sijs may be taken on the recommendations of the team.

\section{$X$. INFORMATION SYSTEM ANALYSIS}

Every term of the permanent function provides a distinct way for analyzing of Information System. For example, one term of the first group consists of five distinct subsystems,S1,S2,S3,S4,S5 .It means solution of five subsystems available offthe- shelf in the global market can analyzed and selected optimally.Similarly,a term in the third group e.g.S212S3S4S5 suggest that only four subsystems are to be considered instead of five. These four subsystems are dyad of two subsystems $\mathrm{S} 1 \& S 2$, and independent S3, S4\&S5.In this manner the terms of all the $(\mathrm{N}+1)$ groups analyzes the system from different angles. The analysis can be carried out from the point of view of structure integration, responsiveness, efficiency, cost and market strategy and strategic partners. The analysis also results in a number of alternative solutions of information system (IS) in the hands of decision makers.

\section{USEFULNESS OF THE PROPOSED METHODOLOGY}

It helps to develop a variety of information system (IS) approaches providing optimum performance characteristics under different organizational applications. Thus, the approach helps to express the information system (IS) in quantitative terms, which has more often been expressed in qualitative terms. The procedure also helps to compare different information system (IS) in terms of its characteristics and rate them for particular 
applications. It is hoped that this methodology will provide a new direction in the research attempts towards global projects of quantitative structure activity relationship (QSAR) and quantitative structure properties relationship (QSPR) (Liu, Uhlherr, and Bannister, 2004; Katritzky, Karelson, and Lobanov; 1997). The present work is an attempt towards the development of complete methodology for virtual implementation (Choi and Chan, 2004) of SCM as well as virtual design of complete information system consisting of Strategic Planning of IT, Virtual Enterprise E-Commerce and from the point of view of Infrastructure and Knowledge and IT Management subsystem. The proposed methodology is a powerful tool in the hands of the designer. Using this and morphological chart/tree, the designer can generate alternative design solutions and select the optimum one after carrying out cause and effect analysis and SWOT analysis. This methodology gives a comprehensive knowledge to the user about information system in SCM and helps in the selection of right product/process/services at the right time and at right cost from the global market.

\section{UNDERPINNING ASSUMPTIONS}

Following assumptions are identified to understand applicability, limitations, comprehensiveness and usefulness of different models.

Graph Theoretical model of the structure of the Information system is based on the assumption that the structure of the system can be correlated quantitvely with its performance e.g,productivity,quality, relaibilty etc.,

Identification set, equation (9) characterizes Information system on the basis of structural components of variable permanent function.

Co efficient of similarity and dissimilarity carry out comparison on the basis of structure only.

Variable permanent matrix is capable of storing every information related to a real life situation of a typical Information system as all its elements are variables and functions of characterizing attributes. This is possible by associating a vector of attributes representing subsystems (i.e. Diagonal Elements) and interconnections (i.e. off diagonal elements).These attributes, if identified comprehensively, the matri represents the Information system completely.

Permanent function of the VPM characterizes uniquely the Information system from the point of view of structure. It is most generalized and comprehensive characterization of the Information system.

Strategic Planning of IT, Virtual Enterprise ECommerce, IT Infrastructure and Knowledge and IT
Management system are the subsets of total Information system and can be derived from and represented by subsets of variable permanent matrix and functions of Information system.

Performance of Information system depends on individual performance of subsystems, sub-subsystems and their components along with interactions/interdependences/influences between them.

Total Information system, its subsystems and their interactions of the organization under consideration depend upon its aims and objectives, value system and business strategy.

Modeling/Methodology is based on bottom up approach. Permanent function values of subsubsystems are used in permanent matrices of the subsyatems.Permanent function values of subsystems are used to calculate permanent function of overall Information system.

\section{XIII.STEP-BY-STEP PROCEDURE FOR INDUSTRYIORGANIZATION}

To assist any company to develop it's our Information System (IS) in SCMs, the following step-bystep procedure is proposed

Step 1: Consider the desired information system. Study the complete information system and its subsystems (Strategic Planning of T, Virtual Enterprise ECommerce, Infrastructure and Knowledge and IT Management system), and also their interactions.

Step 2: Develop a block diagram of the Information System, considering its subsystems and interactions along with assumptions, if any.

Step 3: Develop a systems graph of the information System with subsystems as nodes and edges for interconnection between the nodes (see Fig. 3 for details).

Step 4: Develop the matrix and multinomial representations of Information System (see Fig. 2 for details).

Step 5: Evaluate functions/values of diagonal systems from the permanent functions of distinct subsystems of the information system and repeat Steps 2-4 for each subsystem.

Step 6: Identify the functions/values of off-diagonal systems/interconnections at different levels of hierarchy of the information System, which are systems, subsystems, sub subsystems, etc. 
The values (or functions) of interactions $\mathrm{Sij}$ (i, $\mathrm{j}=1,2$, . .., N) between different subsystems $\mathrm{S} 1, \mathrm{~S} 2, \ldots, \mathrm{SN}$ can be written as a multinomial or a matrix, depending upon the type of interaction/reaction between the two subsystems. The sub subsystems can again be treated as systems, as every sub subsystem is a system in itself. Following the above procedure, these subsystems can be broken down into sub subsystems and different graph, matrix, and permanent representations can be obtained. Depending upon the depth of analysis required, the process could be taken to the constituent level and further. In certain cases, it may be possible to evaluate Sij's experimentally or using available mathematical models.

With the help of this data, complete multinomial for the Information System can be evaluated.

Step 7: carry out critical analysis of the system from structural, functional and performance point of view considering one term at a time. This is necessary to understand strength, weakness, opportunities and threats and then taking decision from the point of view of business strategy.

Step 8: identification code, coefficient of similarity and dissimilarity can be calculated between candidate solutions for taking decision.

With the help this procedure any company can develop its own information system in supply chain, subsystems and developed procedure for taking right decision at right time.

\section{CONCLUSIONS}

The proposed systems methodology for developing a information system by considering all attributes responsible for development, and implementation, along with interactions between the constituents and using a digraph and matrix approach is a powerful tool for structural modeling information system constituents and their interaction with each other. The present work identifies five characteristics/subsystems, which parameterize the information system. The systems methodology consists of the Information System digraph, the ISSCM matrix, and the IS-SCM permanent function. The information system digraph is the mathematical representation of the structural characteristics and their interdependence, useful for visual modeling and analysis. The IS-SCM matrix converts digraph into another mathematical form. This matrix representation is a powerful tool for storage and retrieval of information system in computer database and also for computer processing. The ISSCM permanent function is a unique mathematical model characterizing the structure of the information system irrespective of labeling of subsystems and also helps one to determine the ISSCM index. Different terms of the permanent function lead to a set of analysis tests for strength, weakness, improvement, and optimization of information system. This multi-attribute (structural constituent) characterization of information system converts into a single numerical index, if multivariable Sis and Sijs are represented by numerical values in the variable adjacency matrix. Thus, the numerical index of a IS-SCM derived from a multinomial is used for comparison, rating, and optimum selection. The derivation and importance of the numerical index of a ISSCM will be given in future work with illustrative examples. The present work emphasizes the numerical methodology of information system that can also optimize the design and the production parameters. A generalized methodology is also proposed to model a system consisting of $\mathrm{N}$ subsystems and their interactions. This study gives a criterion how to compare two information systems with the help of permanent function on structure basis. The step by step procedure is a useful guidance for any industry with different business strategies to implement this information system in SCM based on graph theoretic systems approach. The approach integrates all possible structural functional and performance parameters in a mathematical model for analysis and optimization. An attempt will be made in future publications to correlate information system performance characteristics with the ISSCM structural model reported in this article.

\section{REFERENCES}

[1] Bharadwaj, A.S. 2000, A resource-based perspective on information Technology capability and Firm performance: an empirical Investigation, MIS Quarterly, Vol. 24, pp. 169-96.

[2] Byrd, T.A. and Davidson, N.W. 2000, Examining possible antecedents of IT Impact on the Supply chain and its effect on firm performance, Information \& Management, Vol.4, pp. 243-55.

[3] Chen, I.J., Paulraj, A. and Lado, A.A. 2004, Strategic purchasing, supply Management, and firm Performance, Journal of Operations Management, Vol. 22, pp.505-23.

[4] Chinho el al 2006, Identifying the pivotal role of participation strategies and Information Technology application for supply chain excellence, Industrial Management \& Data Systems, Vol. 106, pp. 739756. 
[5] Choy, K.L., Fan, K.K.H. and Lo, V. 2003, Development of an intelligent Customersupplier Relationship management system: the application of case-based reasoning, Industrial Management \& Data Systems, Vol. 103, pp. 263-75.

[6] Christopher, M. 2000,The agile supply chain competing in volatile Markets, Industrial Marketing Management, Vol. 29, pp. 37-44.

[7] Disney, S.M., Naim, M.M., Potter, A., 2004 Assessing the impact of e-Business on Supply chain Dynamics, InternationalJournal of Production Economics, Vol.89.pp.109-118.

[8] Droge, C., Jayaram, J. and Vickery, S.K. 2004, The effects of internal versus External Integration Practices on time-based performance and overall firm performance, Journal of Operations Management, Vol. 22, pp. 557-73.

[9] Gandhi, O.Pz.and Agrawal, V.P. 1996 Failure Cause Analysis-A Structural Approach, Journal of Pressure Vessel Technology Trans ASME, Vol.118, pp.434-440.

[10] Graham, G., Hardaker, G., 2000, Supplychain management across the Internet, International Journal of Physical Distribution \& Logistics Management, Vol.30, pp.286-295.

[11] Gunasekaran, A. and Ngai, E.W.T. 2004), Information systems in supply chain Integration and Management, European Journal of Operational Research, Vol. 159, pp. 269-95.

[12] Handfield, R.B. and Nichols, E.L. Jr 1999, Introduction to Supply Chain Management, PrenticeHall, Englewood Cliffs.

[13] Kannan, V.R. and Tan, K.C. 2005, Just in time, total quality management, and Supply chain Management: understanding their linkages and impact on Business performance, The International Journal of Management Science, Vol.133, pp. 15362.

[14] Kearns, G.S. and Lederer, A.L. 2004, The impact of industry contextual Factors on IT focus and the use of IT for competitive advantage, Information Management, Vol. 41, pp. 899-919.
[15] Lin, C., Chow, W.S., Madu, C.N., Kuei, C.H. and Yu, P.P. 2005, A structural Model of Supply Chain quality management and performance, International Journal of Production Economics, Vol. 96, pp. 35565.

[16] Manrodt, K.B. and Davis, F.W. Jr 1993, The evolution to service response Logistics, International Journal of Physical Distribution \& Logistics Management, Vol. 23, pp. 56-64.

[17] Mohan, M., Gandhi, O.P.and Agrawal, V.P. 2003,Systems modeling of a Coal-Based Steam Power Plant, Journal of Power and energy, Vol.217, pp.59-277.

[18] Nambisan, S. 2000,EC and supply chain management: Towards cross-Industry Supply chains Electronic Markets, Vol.10, pp.197-202.

[19] Narasimhan, R. 2001, Information system utilization strategy for supply chain Integration, Journal of Business Logistics, Vol.22, pp.51-76.

[20] Rahman, Z. 2004 Use of internet in supply chain management: a study of Indian Companies, Industrial Management \& Data Systems, Vol.104, pp.31-41.

[21] Robinson, D.F.and Foulds, L.R. 1980 Digraphs: Theory and Techniques, Gordon and Breach Science Publishers, London.

[22] Sandeep, G., Agrawal, V.P.and Khan, I.A. 2004,A Digraph Approach to TQM Evaluation of An Industry, International journal of Production Research, Vol.42.pp.4031-4053.

[23] Sanders, N.R. and Premus, R. 2002 IT applications in supply chain organizations: A link Between Competitive priorities and organizational benefits, Journal of Business Logistics, Vol. 23, pp. 65-83.

[24] Simchi-Levi, D., Kaminsky, P., Simchi-Levi, E., 2000 Designing and Managing the Supply Chain:Concepts, Strategies and Case Studies, McGraw-Hill International Edition, Singapore.

[25] Soliman, F. andYoussef, M. 2003, Internetbased ecommerce and its impact On Manufacturing and business operation, Industrial Management \& Data Systems, Vol.103, pp. 546-53. 
[26] Tan, G. W., Shaw, M. J. \& Fulkerson, W. 2000,. Webbased global supply Chain Management. In $\mathrm{M}$. Shaw, R. Blanning,T. Strader, \& A. Whinston (Eds.),Handbook on electronic commerce (pp.457478).

[27] Trappey, A.J.C., Trappey, C.V., Hou, J.L. and Chen, B.J.G. 2004 Mobile Agent Technology and Application for online global logistic services, Industrial Management \& Data Systems, Vol. 104, pp. 169-84.

[28] Venkataswamy, R.and Agrawal, V.P. 1997, ADigraph Approach to Quality Evaluation of an Automatic Vehicle, Quality Engineering, Vol.9, pp.405-417.
[29] Wang, M. and Zhang, S. 2005 Integrating EDI with an E-SCM system using EAI Technology, Information Systems Management, Vol. 22 No. 3.pp 49-59

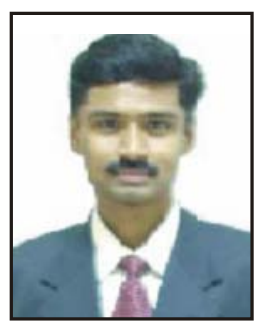

K.J.Sabareesan, faculty in Mechanical Engineering-Birla Institute of Technology and Science, Pilani, Goa campus, Goa, India, has obtained his BE Production Engineering and ME Industrial Engineering degree from Bharathiar University, Coimbatore, Tamilnadu, India. He teaches undergraduate courses in Mechanical Engineering. His major research interests are Supply Chain Network, Computer Integrated Manufacturing, Soft Computing, Graph Theory, and Mathematical Modeling. 